\title{
Eficácia do monepantel no controle da helmintose de ovinos na região de Ivaiporã, no estado do Paraná
}

Michele Monteiro Sudak, José Victor Pronievicz Barreto, Maria Carolina Ricciardi Sbizera, Daiene Locoman, Diego Fagner Michelassi de Souza, Manuela Venturelli Finco, Marcela Lucas de Lima, Luiz Fernando Coelho da Cunha Filho

Universidade Norte do Paraná (UNOPAR), Arapongas, PR, Brasil

*Autor correspondente

e-mail: michele.sudak@hotmail.com

\section{Resumo}

O monepantel bloqueia parte do receptor acetilcolina nicotínico, causando paralisia e a morte dos parasitas. O objetivo da pesquisa foi determinar a eficácia do monepantel no controle da helmintose em ovinos na região de Ivaiporã, no estado do Paraná. 0 experimento foi realizado em três propriedades criadoras de ovinos, localizadas no município de Ivaiporã, durante os meses de fevereiro a abril de 2014. No experimento foram utilizados 40 ovinos na propriedade A, 38 ovinos na propriedade B e 40 ovinos na propriedade C. 0 peso médio dos animais era de $35 \mathrm{~kg}$, com idade entre quatro meses a cinco anos. Não foi administrado nenhum anti-helmíntico 60 dias antes do experimento. 0 critério para a inclusão dos animais no presente experimento foi o método de contagem prévia de OPG, devendo esta ser igual ou superior a 300, onde foram selecionados os animais com médias semelhantes e, assim, distribuídos em dois grupos: GC (grupo controle) e GT (grupo tratado). No grupo GT foi administrado monepantel na dose de 2,5 $\mathrm{mg} / \mathrm{kg}$ de peso vivo. 0 grupo GC não recebeu nenhum tratamento com anti-helmíntico. Todos os animais foram submetidos à coleta de material fecal diretamente da ampola retal no primeiro dia (D0) e no $14^{\circ}$ dia do experimento (D14), para realização de OPG e coprocultura. A partir dos valores de contagem do OPG do D0 e D14, realizou-se o teste de redução de contagem de ovos por gramas de fezes (FERC - Faecal Egg Cout Redution Test) utilizando a fórmula FECR \% = (1- T2/T1 x C1/C2) x 100, descrita por Boersema e Pandey (1997), para determinar a eficácia dos produtos, por comparação da contagem de OPG, antes e após o tratamento. 0 medicamento é considerado eficaz quando há uma redução de OPG superior a 90\%. A redução na contagem de ovos nas fezes (RCOF), após o tratamento com monepantel, foi de 98,67\% na propriedade A, 99,81\% na propriedade B, e 99,29\% na propriedade C, o que evidencia redução significativa da contagem de ovos nas fezes após a administração do monepantel. No presente trabalho os resultados da coprocultura demonstraram que os gêneros mais resistentes foram Haemonchus spp., Trichostrongylus spp., Ostertagia spp. e Cooperia spp. Conclui-se que o monepantel foi altamente eficaz na redução da helmintose em ovinos. 